\title{
Ensino de leitura e escrita através do pareamento com o modelo e seus efeitos sobre medidas de inteligência
}

\author{
José Gonçalves Medeiros \\ Sonia Aparecida Teixeira \\ Universidade Federal de Santa Catarina
}

\begin{abstract}
Resumo
Dois grupos (G1 e G2) de três crianças, entre oito e doze anos, repetentes, participaram do estudo. Ambos foram submetidos à aplicação do WISC e do IAR no início e final do estudo. O G1 foi submetido a um treino de discriminações condicionais, com palavras faladas como modelos e palavras impressas como comparação. Todas as crianças do G1 aprenderam a ler, com aumento maior de QI do que as crianças do G2. Nos testes apresentaram porcentagem elevada de leitura das palavras ensinadas e de generalização. No IAR, tanto os sujeitos do G1 quanto do G2 apresentaram mudanças nas habilidades medidas pelo teste, em especial, lateralidade, análise-síntese e coordenação motora, com maior porcentagem de itens alterados para os sujeitos do G1. Os resultados indicam a existência de uma relação entre a emergência de leitura generalizada e aumento de QI.

Palavras-chave: Discriminação condicional, fracasso escolar, equivalência de estímulos.
\end{abstract}

\footnotetext{
Abstract

Teaching and writing through matching to sample and its effects on intelligence measures

Two groups (G1 and G2) consisting of three flunked children each, ranging from eight to twelve years old, participated in the study. Both groups were given the WISC and IAR tests at
} 
Key words: conditional discrimination, school failure,

stimulus equivalence. the beginning and at the end of the study. G1 underwent a training of conditional discriminations, with words spoken as sample and words printed as comparison. All the children of G1 learned how to read, with greater increase of IQ than the children of G2. In the tests they presented high percentage of reading of the taught and of the generalized words. In IAR, both the subjects of G1 and of the G2 showed changes in the measured abilities for the test, especially, laterality, analysissynthesis and motor coordination, with larger percentage of items altered for the G1 subjects. The results indicate the existence of a relationship between the emergence of generalized reading and increase of IQ.

$\mathrm{O}$ presente trabalho fez parte de um projeto mais amplo, desen volvido numa escola da periferia, cuja proposta foi o ensino de novas palavras a crianças com desempenho acadêmico que não atendiam às exigências do ensino formal. Empregou-se o procedimento de discriminação condicional, associado à técnica de exclusão, onde o aluno aprende a reconhecer palavras através de determinadas configurações de estímulos e consegue, a partir destas relações aprendidas, responder a novas relações (denominadas emergentes ou generalizadas).

Essas relações emergentes, ensinadas indiretamente, seriam resultado da formação de classes de estímulos equivalentes. Segundo a definição de Sidman e Tailby (1982) para que a equivalência de estímulos seja observada, é preciso que as relações entre os estímulos mostrem, numa relação condicional, as propriedades de reflexividade, simetria e transitividade. Estas se evidenciam, por exemplo, a partir do ensino de relações entre figuras, palavras impressas e palavras ditadas. A formação de uma classe envolvendo a equivalência entre estes três tipos de estímulos é a base da leitura com compreensão (Mackay \& Sidman, 1984). 
A aprendizagem como resultado de intervenções educacionais contrapõe-se, segundo Ribes (1981), à concepção da existência de uma capacidade subjacente como determinante desta aprendizagem. Esta capacidade pode ser reduzida a um conceito hipotético tanto quanto pode ser atribuída a um funcionamento, também suposto, de certas áreas privilegiadas do sistema nervoso central. Schoenfeld (1974) e Bijou (1976) apontam argumentos que invalidam a aceitação de resultados de testes de inteligência como indicadores de uma suposta capacidade ou de que tais resultados refletiriam diferenças de ordem genética entre os indivíduos. Afirma Bijou:

(...) tanto as variáveis ambientais como as hereditárias são importantes na determinação de qualquer traço biológico ou característica psicológica. Nem as influências hereditárias, nem as ambientais podem existir uma sem a outra; ambas são componentes essenciais que interagem continuamente e conseqüentemente exercem influência desde o momento da concepção. Não há organismos sem genótipos e não há genótipos sem um ambiente (p. 86).

Pesquisadores de centros importantes, com tradição em pesquisa, têm trabalhado com esta temática e argumentam na mesma direção dos autores acima apontados. Carraher, Carraher e Schliemann (1987) utilizaram em suas pesquisas metodologia mista que combina o método clínico piagetiano com o etnográfico e mostraram que

as crianças de baixa renda não apresentam um déficit individual, mas apresentam um desenvolvimento cognitivo diferente daquele apresentado pelas crianças mais favorecidas sócio-economicamente, embora as primeiras possam ser consideradas defasadas quando comparadas às segundas, numa mesma faixa etária, no contexto escolar (p. 20).

Para Chiarottino, Carraher e Schliemann (1987), o déficit cognitivo (quando afastada a hipótese de comprometimento orgânico) deve ser atribuído simultaneamente à interrupção do desenvolvimento endógeno das estruturas de pensamento e à precariedade de estimulação do contexto sócio cultural, como acontece com os indivíduos de baixa renda; estes indivíduos estão em situação de desvantagem cognitiva 
real porque não tiveram a oportunidade de serem solicitados pelo contexto sócio cultural e nem puderam desenvolver suas potencialidades cognitivas, embora esta defasagem possa ser temporária, desde que sejam estimuladas a superá-las. De acordo com Chiarottino (1972), qualquer déficit ou desenvolvimento da inteligência depende da interação do indivíduo com o contexto.

Neto (1994), escrevendo sobre o assunto na Folha de São Paulo e destacando em manchete que "QI mede comportamento inteligente" diz que...

(...) o debate ainda é mais político do que científico, não é possível medir a "inteligência", seja lá o que ela for, diretamente, assim como só é possível saber a distância das estrelas estudando-se a luz que emitem. Medir inteligência significa medir comportamentos considerados "inteligentes", como dar as respostas certas em um teste de QI (p. 4).

A inteligência também não é algo fácil de comparar, apesar dos testes de QI passarem esta impressão ao especificarem uma média "normal" de 100, ou de "genial" para acima de 130, ou "retardado" para valores inferiores à média. Existem, por definição, diferentes composições da "inteligência": de habilidades espaciais, de memória, de raciocínio, de verbalização etc.

Para Marques (1987), a concepção do significado de inteligência estaria impregnada de um relativismo cultural, ou seja, o conceito de inteligência é concebido de acordo com a visão de mundo por diferentes grupos culturais; o conceito de inteligência é equacionado com necessidades e aspirações culturais e sociais que se relacionam a valores e finalidades (Almeida, 1988; Anastasi, 1983) que são histórica e socialmente produzidos.

Nos últimos anos, alguns autores têm apontado para a predominância de uma relação inversa entre inteligência e aprendizagem. A explicação de uma relação entre inteligência e aprendizagem escolar está cedendo espaço para uma explicação oposta, ou seja, da aprendizagem para a inteligência. Anastasi (1983) e Almeida (1988) afirmam que uma forma de conceber a influência da aprendizagem na inteligência decorre dos estudos no âmbito da teoria da "diferenciação 
cognitiva progressiva' que, segundo eles, decorre de uma progressiva diferenciação intelectual dos indivíduos ou cristalização de formas específicas de desempenho cognitivo como reflexo de suas aprendizagens anteriores. Almeida (1992), um dos que questiona a explicação baseada na relação tradicional, afirma:

(...) um aluno com melhores professores, com mais tempo, com metodologias de ensino mais adequadas ou métodos de estudo mais eficazes ou com maior motivação e expectativa positiva do seu sucesso na área das matemáticas do que nas humanas, virá a apresentar no futuro níveis mais elevados de desempenho nos testes de aptidão numérica do que nos testes de aptidão verbal. Há esta possibilidade de afetarmos o desenvolvimento cognitivo e a inteligência do indivíduo através da qualidade das situações educativas... (p. 285).

Um crescente número de estudos (de Rose, Souza, Rossito \& de Rose, 1989; Hanna et al., 1993; Medeiros, Konescki, \& Souza, 1993; Medeiros, Monteiro \& Silva, 1997; Medeiros, Antonakopoulu, Amorim \& Righetto, 1997; Medeiros, 1997; Stromer \& Mackay, 1992) tem demonstrado que a aprendizagem de discriminações condicionais pode levar os sujeitos a exibir não apenas o comportamento que foi explicitamente ensinado mas também comportamentos novos que emergem sem treino específico. Este tipo de fenômeno tem despertado crescente interesse no campo da Análise Experimental do Comportamento, uma vez que aponta para a possibilidade de mostrar como a novidade no comportamento humano pode se relacionar de maneira ordenada ao desempenho explicitamente ensinado. É possível, segundo de Rose (1993), com procedimentos desta natureza, caminhar em direção a uma teoria comportamental que compreenda a esfera da atividade humana que é referida sob a rubrica da cognição. Pode-se, também, por esta via, compreender a "produtividade" do comportamento humano. Há, ainda, segundo de Rose, possibilidades de derivar procedimentos que possam servir como alternativa em casos onde esta "produtividade" do comportamento esteja comprometida.

Uma limitação encontrada em sujeitos deficientes mentais ou com problemas de aprendizagem é a dificuldade em extrapolar para além dos limites do que lhes foi ensinado. Desse modo, os estudos de 
equivalência de estímulos oferecem um paradigma a ser explorado no ensino, especialmente no ensino de indivíduos que apresentam dificuldades de aprender pelos métodos convencionais. Já foram relatados estudos aplicando este paradigma ao ensino de habilidades de leitura e escrita a deficientes mentais (Mackay, 1985; Mackay \& Sidman, 1984) e ao ensino de habilidades de uso de moedas em sujeitos severamente retardados (Mc Donagh, McIlvane \& Stoddard, 1984). Stromer (1991) relata a revisão que Singh e Singh (1986) realizaram em relação às pesquisas sobre ensino de leitura para retardados mentais onde, segundo eles, os procedimentos baseados na equivalência de Sidman foram "exemplares em termos de sofisticação metodológica e consistem na melhor evidência de que habilidades básicas de leitura podem ser ensinadas para esta população..." (p. 190).

Não seria este também um dos caminhos para explicar os chamados comportamentos criativos, englobados sob o rótulo de criatividade? Segundo de Rose (1988), estaríamos caminhando em direção a uma perspectiva bastante concreta para se lidar com os fenômenos cognitivos em termos de processos comportamentais. E, possivelmente, a uma profícua compreensão das relações entre pensamento e linguagem e talvez entre inteligência e comportamento.

O presente estudo apresenta semelhanças ${ }^{1}$ metodológicas ao realizado por de Rose et al. (1993). Estes autores procuraram relacionar a mudança nas medidas de QI com a ocorrência de generalização em leitura e escrita. Os sujeitos do GE foram submetidos a um programa de ensino de habilidades de leitura e escrita, no qual a generalização foi medida ao final do programa, tanto quanto o QI dos sujeitos foi avaliado antes e depois da aplicação do programa de ensino (medido pelo WISC); os sujeitos do GC não foram submetidos ao programa de ensino, tendo sido avaliados periodicamente em leitura e escrita. Os sujeitos do GE apresentaram generalização de leitura correlacionada com aumento de QI. Os sujeitos do GC foram depois submetidos a uma versão modificada do primeiro programa, omitindo-se o treino de cópia das palavras a partir das letras soltas (composição de anagrama). Apenas um sujeito deste grupo apresentou generalização ao final do primeiro programa, ou seja, em leitura, ao contrário dos sujeitos do GE que apresentaram generalização em leitura, composição e escri- 
ta. Os sujeitos do GC apresentaram flutuações assistemáticas na medida do QI, sem relação com a ocorrência de generalização.

Seria a capacidade para aprender resultado exclusivo de intervenções educacionais ou, como se depara com frequiência, fruto das características pessoais, principalmente do nível de inteligência da criança? Procurando responder a esta pergunta, o presente estudo teve como objetivos: (1) verificar que efeitos um procedimento de discriminação condicional produz sobre os escores de QI de crianças com problemas de desenvolvimento, aqui definidos como crianças cujos resultados nos testes de QI encontram-se abaixo da faixa de normalidade e que apresentam dificuldades na aquisição da leitura e escrita; (2) verificar que aspectos do procedimento de discriminação condicional podem estar relacionados com as alterações nos resultados dos testes utilizados para medir o quociente de inteligência (WISC) e prérequisitos básicos para o início da alfabetização (IAR).

\section{Método}

\section{Sujeitos}

Participaram deste trabalho seis crianças de uma sala de aula da $1^{\mathrm{a}}$ série do ensino fundamental, que apresentavam dificuldades na aquisição do repertório de leitura e escrita. A sala de aula era composta por crianças do sexo masculino e feminino, com idade variando entre $8 \mathrm{e}$ 12 anos, alunos da Escola Estadual Professora Laura Lima, localizada no bairro Monte Verde, em Florianópolis, SC. Eram crianças com história de fracasso escolar, cujos pais, na maioria dos casos, pertencem à classe sócio-econômica baixa.

\section{Escolha dos sujeitos}

O procedimento teve inicio com a aplicação do WISC (Teste de Inteligência) e o IAR (Instrumento de Avaliação do Repertório Comportamental) nas seis crianças indicadas pela professora e consideradas por ela como sendo as que apresentavam maiores dificuldades em sala de aula. Na medida em que o objetivo do trabalho era primeiramente ensinar leitura e escrita a crianças com dificuldades de aprendizagem, aquelas que obtiveram resultados mais baixos fizeram 
parte do G1 (submetido ao procedimento experimental) e as que obtiveram resultados mais altos fizeram parte do G2 (participou apenas do procedimento de avaliação através do testes WISC e IAR).

\section{Situação e material}

O WISC (Wechsler, 1949) é uma bateria de testes de inteligência, cujas medidas, objetivas e padronizadas, resultaram de um procedimento de amostragem. Consiste de 12 testes, divididos em dois subgrupos, identificados como verbais e de execução. Com a finalidade de reduzir o tempo de aplicação, foram aplicados dez testes, cinco verbais e cinco de execução.

O IAR (Leite, 1984) é um instrumento que tem como finalidade verificar o nível de desempenho de lateralidade, de posição, de identificação de cores, de esquema corporal, de direção, de espaço, de tamanho, de quantidade, de forma, de discriminação visual, de discriminação auditiva, de análise-síntese e de coordenação motora fina e que são considerados pelo autor como pré-requisitos para que o processo de alfabetização ocorra com sucesso.

As sessões de aprendizagem foram realizadas nas dependências de uma sala de aula da Escola, desativada para esta finalidade.

Os estímulos visuais, constituídos de palavras impressas, fonte arial, "bold", tamanho 52 do processador de texto do Word for Windows 2.0 e figuras coloridas, de aproximadamente $4 \mathrm{~cm}$ de altura por $4 \mathrm{~cm}$ de largura, foram colados em folhas de papel tamanho ofício e encaixadas em pastas plásticas. Pedaços de cartolinas, de $3 \mathrm{~cm}$ de largura por $3 \mathrm{~cm}$ de comprimento, com letras do tamanho acima citado e coladas em sua superfície, foram utilizadas na atividade de montagem das palavras que estavam sendo ensinadas. Todo o material permaneceu sobre uma mesa ao redor da qual sentavam, frente a frente, o sujeito e o experimentador.

\section{Procedimento}

Foram selecionados, por indicação da professora, seis alunos de uma mesma classe que, além de apresentarem uma história de fracasso escolar, mostravam um repertório de leitura e escrita defasado em relação ao restante da turma. Três deles (Grupo 1-G1) foram submetidos 
à aplicação do WISC e do IAR e ao procedimento que segue descrito, além de continuarem também suas atividades regulares em sala de aula quando não participavam do procedimento experimental. Os outros três sujeitos (Grupo $2^{2}-\mathrm{G} 2$ ) foram avaliados apenas através da aplicação do WISC e do IAR, sem participação em qualquer outra fase do procedimento experimental, continuando normalmente suas atividades em sala de aula.

Os sujeitos do G1 foram submetidos ao conjunto de procedimentos que compõem o programa de ensino individualizado e que se assemelha àquele utilizado por de Rose et al. (1989). O procedimento principal foi o de exclusão, usado para expandir gradualmente, ao longo de uma sequiência de passos, o repertório de pareamentos entre modelos (palavras ditadas pelo experimentador) e estímulos de comparação (palavras impressas). A base do procedimento de exclusão consiste na presença, em cada tentativa de pareamento, de um estímulo de comparação conhecido pelo sujeito, apresentado juntamente com outro estímulo. Quando o experimentador apresentava o modelo correspondente ao estímulo de comparação novo, o estímulo de comparação já conhecido funcionava como pista ou deixa para que o sujeito o rejeitasse e selecionasse corretamente o estímulo de comparação novo.

O programa também envolveu pré e pós-testes para verificar a aquisição de leitura - tanto de palavras não explicitamente ensinadas (denominadas palavras de generalização), como aquelas ensinadas durante o procedimento (denominadas palavras-treino). Testes adicionais foram conduzidos para verificar a formação de equivalência entre palavra impressa, palavra ditada e figura.

As palavras-treino foram dissílabos ou trissílabos, compostos por sílabas simples, e as palavras de generalização foram obtidas por recombinação das mesmas sílabas simples (foram todos substantivos - nomes de objetos, organismos ou eventos corriqueiros - que presumivelmente fazem parte universo vocabular das crianças).

O programa foi dividido em uma sequiência de passos, cada um consistindo de três etapas: Pré-teste, Exclusão e Pós-teste. Os dois primeiros passos foram destinados à aquisição de uma linha de base 
inicial, que foi sendo expandida com o emprego do procedimento de exclusão. O programa prosseguiu alternando passos de exclusão com passos de equivalência de forma que, a cada dois passos de exclusão, aplicava-se um Teste de Equivalência, no qual era verificada a formação de classes de equivalência entre palavras faladas, palavras impressas e figuras.

Os passos 3 e 4 (de exclusão) envolveram cada um, a introdução de duas palavras-treino (com cinco tentativas de exclusão para cada palavra). A partir do sexto passo de exclusão passaram a ser introduzidas quatro palavras-treino a cada passo e, em cada passo da exclusão, foram introduzidas duas palavras de generalização (resultantes da combinação de sílabas de palavras-treino ensinadas nos passos anteriores). As tentativas iniciais de um passo de exclusão constituíam um pré-teste que avaliava a leitura das palavras-treino a serem introduzidas no passo, a leitura das palavras treinadas na sessão imediatamente anterior (retenção) e também a leitura de duas palavras de generalização. As tentativas finais do passo constituíam um pós-teste que avaliava a leitura das palavras-treino e as de generalização. A leitura correta de todas as palavras treinadas na sessão anterior durante o pré-teste era um requisito para a aplicação de um passo: se o critério não era atingido, o passo anterior era repetido. No caso de ocorrência de $100 \%$ de acerto no pré-teste, o treino era realizado; para ir para o passo seguinte, havia necessidade também de $100 \%$ de acerto das tentativas da exclusão, bem como leitura correta das palavras-treino apresentadas no pós-teste. Passos de equivalência foram realizados depois de cada dois passos de exclusão. Foram também realizados dois testes que verificaram a leitura de todas as palavrastreino e de generalização introduzidas até então. O Teste 1 foi realizado aproximadamente na metade do programa e o Teste 2 foi realizado ao final do programa. Além destes dois testes, foi realizado um Teste de Retenção para verificar a porcentagem de leitura retida após o período de férias.

As respostas corretas foram sempre reforçadas nos passos em que estivesse ocorrendo o procedimento de ensino de novas relações (palavras-treino), através de expressões tipo "muito bem" e "correto". 
O registro das escolhas corretas foi realizado manualmente pelo experimentador.

Cinco procedimentos básicos constituíram as fases do procedimento de alfabetização que foi realizado entre agosto de 1994 a julho de 1995: (1) Linha de Base I; (2) Linha de Base II (Equivalência); (3) Exclusão; (4) Equivalência e (5) Testes, descritas a seguir:

Fase A: Linha de Base I (Passo 1)

Etapa 1 - Teste de leitura: Foram escolhidas 78 palavras dissílabas e trissílabas simples. Estas palavras foram impressas e eram apresentadas ao sujeito, com o experimentador apresentando uma de cada vez e perguntando: “Aponte e leia o que está escrito aqui”. Suas respostas eram então anotadas pelo experimentador como certas ou erradas nas colunas apropriadas. Nenhuma conseqüência era fornecida ao desempenho do sujeito, mesmo que suas respostas estivessem corretas.

As palavras que não foram lidas corretamente constituíram-se na relação de palavras a serem ensinadas.

Etapa 2 - Teste de identificação das figuras: Para cada palavra da relação foi também selecionada a figura correspondente e apresentada ao sujeito, seguindo um procedimento similar àquele do teste de leitura. $O$ experimentador apontava um desenho de cada vez e perguntava: " $O$ que é isto?"; anotava a resposta do sujeito sem elogiá-lo ou corrigi-lo.

Etapa 3 - Pré-teste das figuras e das palavras-treino correspondentes: Nesta etapa, três palavras-treino e as figuras correspondentes eram apresentadas ao sujeito: ao iniciar a sessão, abria-se uma das pastas plásticas contendo as figuras e as palavras impressas (uma em cada folha) e apresentava-se à criança a primeira figura, dizendo-se: "Que figura é essa"?

Nenhuma conseqüência era fornecida para o acerto ou erro da criança. E assim prosseguia com as outras duas figuras. Na sequiência, apresentava-se a primeira palavra e perguntava-se: "Que palavra é essa"? Assim, como no caso das figuras, nenhuma conseqüência era fornecida para o acerto ou erro da criança. Em seguida eram apresentadas as outras duas palavras-treino.

Etapa 4 - Treino inicial : A primeira palavra-treino era apresentada cinco vezes, com o experimentador dizendo: "Esta palavra é tatu". 
Frente à configuração, semelhante à demonstrada na Figura 1 (quadro 1), o experimentador dizia: "Aponte a palavra tatu". Se o sujeito apontasse corretamente a palavra, ele era elogiado com expressões do tipo "muito bem", "correto"; quando o desempenho do sujeito era incorreto, aplicava-se um procedimento de correção que consistia em perguntar-lhe: "Você tem certeza?" Caso o sujeito alterasse sua resposta, aplicava-se o procedimento regular de reforçamento. As respostas eram assinaladas como certas ou erradas na respectiva coluna da folha de resposta. Assim que o sujeito tivesse aprendido uma das "palavras-treino", o experimentador passava a apresentar duas palavras-treino (estímulos comparação), das quais uma delas foi a primeira ensinada, ditando uma delas (a desconhecida) e pedindo para o sujeito apontá-la (por exemplo, "aponte bola"). Se a criança apontasse corretamente o experimentador elogiava-a. Caso contrário, usava o procedimento de correção. Após o sujeito ter apontado para a palavra solicitada, o experimentador pedia ao sujeito que dissesse qual era a outra (aquela ensinada inicialmente). Essa configuração pode ser vista na Figura 1 (quadro 2):

Etapa 5 - Montagem (cópia): Após a primeira tentativa de identificação da primeira palavra-treino, antes da exclusão, dava-se início ao procedimento de montagem dessa palavra, com o experimentador dizendo: "Agora você vai escrever com essas letras a palavra tatu". Se a montagem fosse correta, o experimentador reforçava o desempenho do sujeito com expressões do tipo: "Isso", "Muito bem", "Correto". Na seqüência, o experimentador perguntava ao sujeito: "Que palavra você escreveu?". Se o sujeito lesse corretamente a palavra montada, o experimentador reforçava novamente o desempenho do sujeito com as expressões acima citadas. O mesmo procedimento ocorreu com as outras duas palavras. Se o sujeito não realizasse corretamente a montagem, o experimentador pedia-lhe para tentar outra vez: "Vamos tentar mais uma vez?". Caso o sujeito não conseguisse montar a palavra na segunda tentativa, o experimentador sugeria: "Preste atenção na palavra (o experimentador aponta a palavra impressa). Agora tente montar a palavra".

Etapa 6 - Pós-teste: Terminada a etapa de ensino das palavrastreino, foram apresentadas, de cada vez, duas das palavras ensinadas 

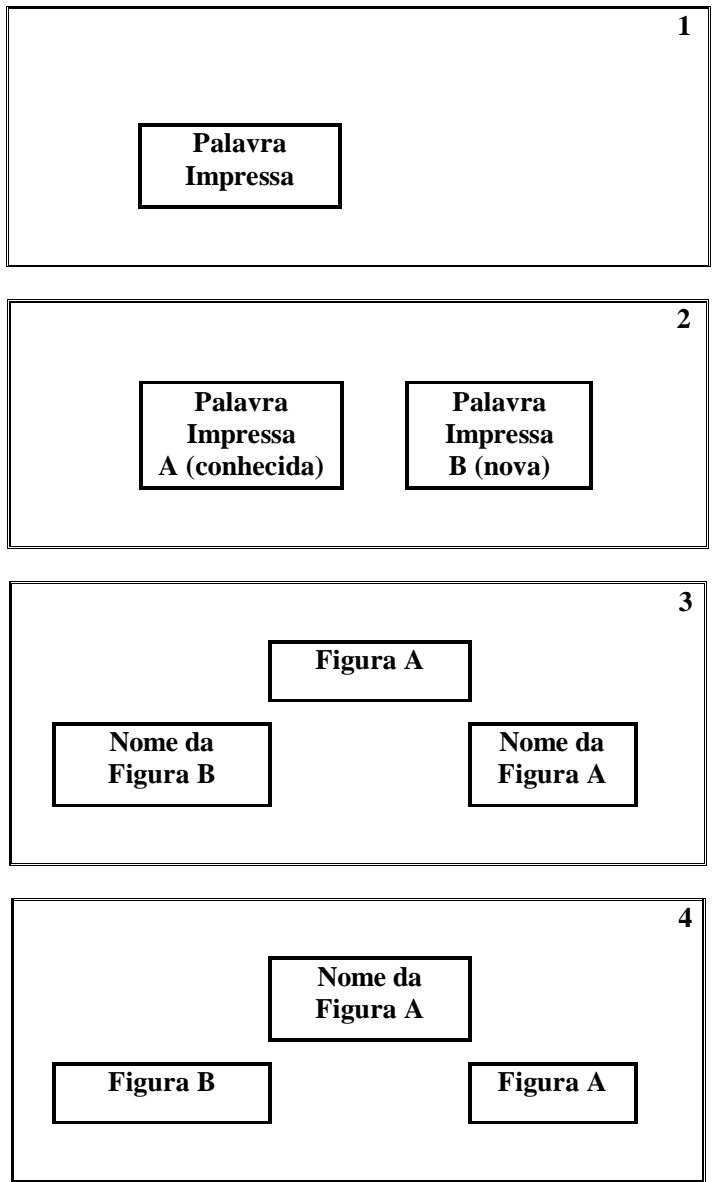

Figura 1. Seqüência do procedimento da primeira palavra ensinada (em 1), da segunda palavra ensinada (em 2) e do procedimento do Teste de Equivalência: figura como modelo (em 3) e nome da figura como modelo (em 4).

na sessão. Procurava-se inverter a posição de cada palavra em tentativas sucessivas. Essas eram cobertas por um cartão e o experimentador dizia: "Agora vou mostrar a você essas palavras e não vou dizer se a sua resposta está certa ou errada”. Descobria-se uma das palavras, com o experimentador solicitando ao sujeito para dizer o nome dela, dizendo: "Aponte e diga que palavra é esta". Em seguida, descobria a 
outra e perguntava: “Qual é a outra?”. O experimentador então anotava a resposta certa ou errada na folha de resposta e nenhuma conseqüência era apresentada ao acerto ou erro da criança.

Fase B: Linha de Base II - Equivalência (Passo 2)

Etapa 1 - Treino de identificação das figuras: Antes de dar início à fase de equivalência apresentavam-se as figuras correspondentes às palavras-treino, uma de cada vez, com o experimentador perguntando: “O que é isto?”. O experimentador reforçava a identificação correta das figuras. Quando o sujeito não identificava corretamente a figura, o experimentador o fazia e perguntava a seguir: "O que é isto?". Caso o sujeito acertasse, então o experimentador elogiava o desempenho correto.

Etapa 2 - Equivalência:

\section{I- Figura como modelo}

Os estímulos usados nesta etapa eram as palavras-treino e respectivas figuras usadas na Fase A (Linha de Base I). A princípio, como visto na Figura 1 (quadro 3), uma folha de papel cobria os estímulos de comparação (parte inferior do quadro). $\mathrm{O}$ experimentador solicitava à criança que apontasse para a figura no alto da página; tendo ela apontado, o experimentador retirava a folha e pedia-lhe que apontasse a palavra que correspondesse ao estímulo-modelo: "Aponte o nome dessa figura". Assim que a criança tivesse apontado, o experimentador perguntava-lhe: “Que palavra é essa?". O experimentador anotava sua resposta na coluna apropriada (certo ou errado) e nenhuma conseqüência era fornecida ao desempenho do sujeito, não importando se a resposta estivesse correta ou incorreta.

II- Nome da figura como modelo

Neste caso, o nome de uma das figuras (palavra impressa) funcionava como modelo e as figuras como estímulos-de-comparação, sendo um deles, o correto. Os estímulos de comparação, como vistos na Figura 1 (quadro 4), estavam cobertos por uma folha de papel (parte inferior do quadro); nessa situação o experimentador dizia: "Aponte a palavra". Após o sujeito ter apontado para a palavra, o experimentador dizia: "Que palavra é essa?" Assim que a criança tivesse apontado e verbalizado, o experimentador perguntava: “Agora aponte o desenho 
correto" e nenhuma conseqüência era fornecida ao desempenho do sujeito, não importando se a resposta estivesse correta ou incorreta.

Fase C: Exclusão (Passos 3, 4, 6, 7, 10, 11, 13, 14, 16, 17)

Etapa 1 - Pré-teste das novas palavras-treino e das figuras correspondentes: Nesta etapa foram apresentadas, uma de cada vez, as três figuras relativas às novas palavras-treino, as três palavras ensinadas na sessão anterior, outras três palavras-treino e duas palavras de generalização; após a apresentação destas figuras e palavras, dava-se início à exclusão.

Etapa 2 - Exclusão: Nesta etapa a palavra nova era sempre apresentada juntamente com uma das palavras-treino (uma das palavras que a criança aprendeu na Fase de Linha de Base I), com o experimentador dizendo: "Qual das palavras é...?". O experimentador dizia o nome da palavra nova (sem apontá-la), colada na base da folha, ao lado da palavra conhecida (como no quadro 2 da Figura 1). Nessa situação, o estímulo modelo era a palavra ditada pelo experimentador (estímulo auditivo) e os estímulos de comparação eram as palavras coladas na base da folha de papel. Se a criança respondesse identificando corretamente a palavra, ela era elogiada com expressões do tipo "muito bem", "correto" etc.; caso a resposta fosse incorreta, o experimentador usava o procedimento de correção, perguntando: "Você tem certeza?". Caso a criança alterasse sua resposta, aplicava-se o procedimento regular de reforçamento das tentativas corretas.

Etapa 3: Montagem (cópia): Tentativas de montagem foram também realizadas (um envelope continha as palavras que estavam sendo ensinadas, porém com as letras separadas). $\mathrm{O}$ experimentador distribuía as letras (que compunham a palavra a ser montada) aleatoriamente sobre a mesa e solicitava à criança que montasse a palavra que estava sendo ensinada. Após a criança ter montado a palavra corretamente, aplicava-se o procedimento regular de reforçamento e solicitava-se à criança que lesse a palavra que ela acabara de montar.

Etapa 4 - Pós-teste das palavras ensinadas na exclusão e das palavras de generalização: Terminada a etapa de ensino das palavrastreino através do procedimento de exclusão, dava-se início ao pósteste, onde as palavras a serem testadas estavam cobertas por uma 
folha de papel, com o experimentador dizendo: "Agora vou mostrarlhe essas palavras e não vou lhe dizer se estão certas ou erradas". O experimentador solicitava ao sujeito para dizer o nome de uma das palavras, dizendo: "Aponte e diga a palavra..." (dizia uma das palavras que foi ensinada, sem apontá-la). Em seguida perguntava: "Qual é a outra?". Nenhuma consequiência era fornecida ao desempenho do sujeito. As respostas eram assinaladas como certas ou erradas na respectiva coluna da folha de respostas. $\mathrm{O}$ mesmo ocorria em relação às duas palavras de generalização.

Fase D: Equivalência (Passos 5, 8, 12, 16 e 18)

$\mathrm{O}$ procedimento foi similar àquele descrito na Etapa 2 da Fase $\mathrm{B}$ (Equivalência, Figura 1, quadros 3 e 4). À diferença daquele, usavamse como estímulos (modelo e de comparação) as palavras e respectivos desenhos extraídos dos dois passos de exclusão precedentes.

Fase F: Teste de Retenção e Testes 1 e 2

Três testes foram realizados. Os Testes 1 e 2 foram utilizados para verificar o percentual de leitura correta frente às palavras-treino introduzidas até o referido passo, bem como a leitura das palavras de generalização novas. O Teste 1 foi realizado no Passo 9 e o Teste 2 no Passo 19. O de Retenção, aplicado após o período de férias, foi usado para verificar o percentual de leitura correta retido durante um período em que não foram organizadas atividades acadêmicas formais.

Terminada a aplicação do Teste 2 (retenção de leitura de todas as palavras-treino e de todas as palavras de generalização), reaplicou-se o WISC e o IAR, tanto nos sujeitos do G1, quanto nos sujeitos do G2.

\section{Resultados}

A Figura 2 apresenta a porcentagem de leitura correta nas etapas de pré e pós-testes, tanto das palavras-treino, quanto das palavras de generalização. Verifica-se no pré-teste das palavras-treino (lado esquerdo da Figura) que há uma maior porcentagem de erros nas sessões iniciais (em geral até à décima) e, na medida em que o procedimento vai se desenvolvendo, o número de erros também diminui com, praticamente, nenhum erro nas sessões finais. O mesmo não ocorre com os pós-testes, nos quais não existem praticamente erros, exceto 

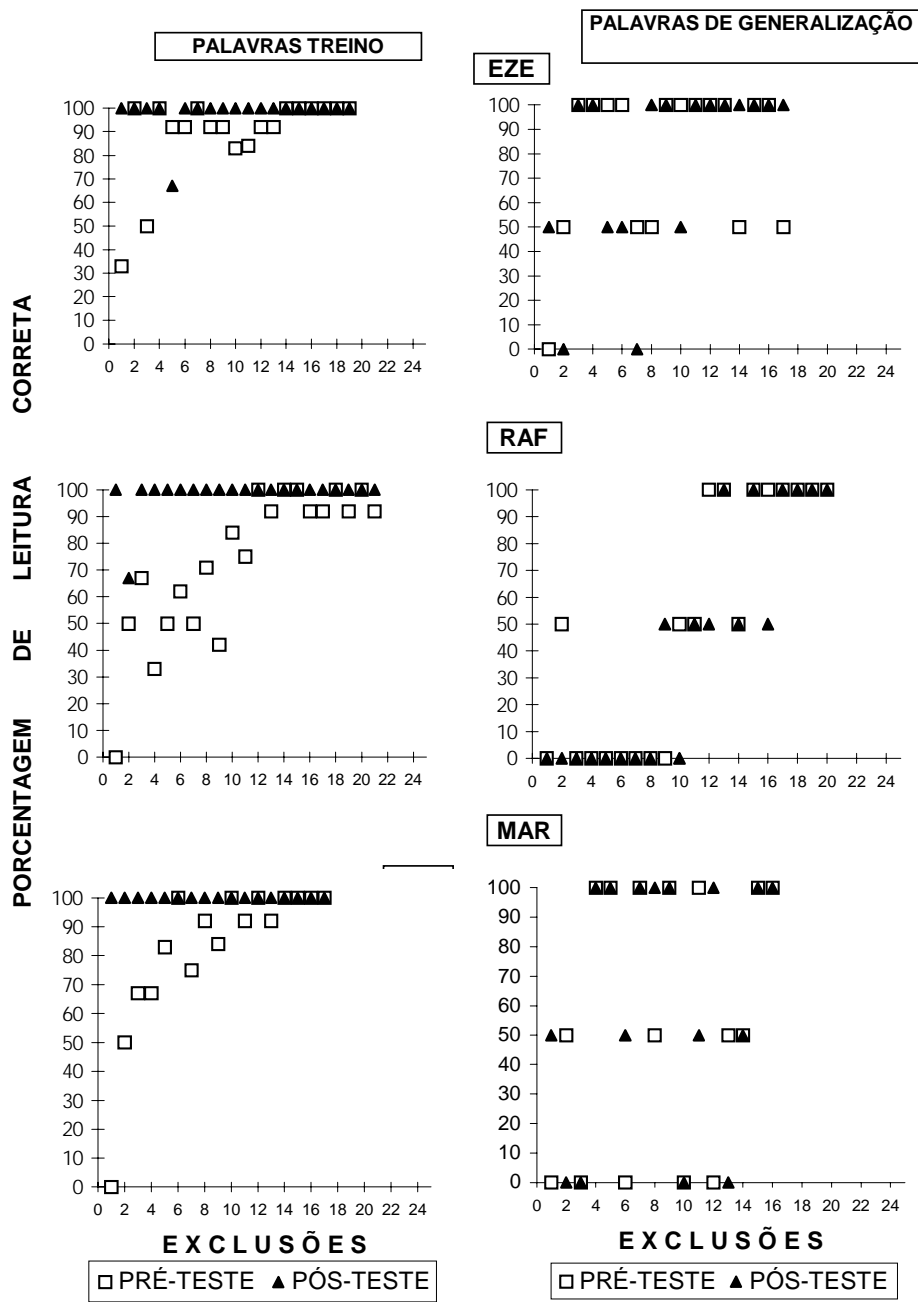

\section{RAF}
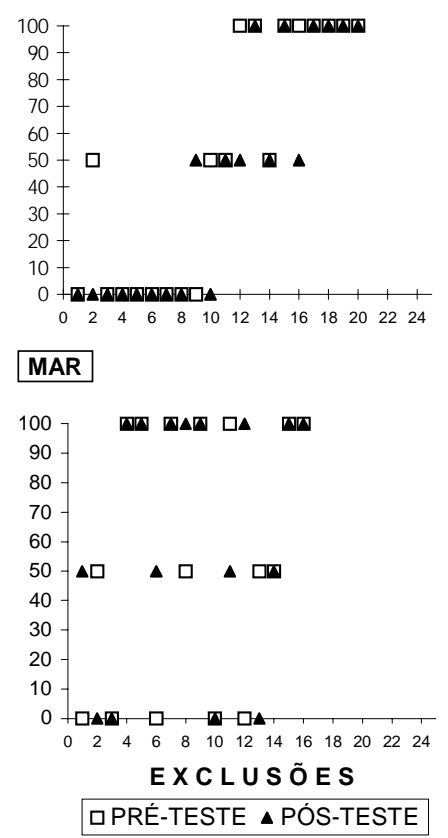

Figura 2. Porcentagem de leitura correta das palavras/treino e das palavras de generalização nos pré e pós-testes dos sujeitos do $\boldsymbol{G} \boldsymbol{I}$. 
na exclusão 5 (65 \%) para o sujeito EZE e na exclusão $2(65 \%)$ para o sujeito RAF.

Em relação às palavras de generalização (lado direito da Figura) a situação é diferente. Verifica-se uma variabilidade mais acentuada ao longo das exclusões (entre 0 e $100 \%$ ), com aumento da porcentagem de acertos nas exclusões finais. O melhor desempenho neste tipo de leitura é o de EZE, com percentuais de acertos de $100 \%$ na maior parte dos pré e pós-testes. RAF, embora demonstrando pouca leitura generalizada nas exclusões iniciais (do início até à $10^{\mathrm{a}}$ exclusão), apresenta, nas quatro últimas exclusões, leitura generalizada com $100 \%$ de acerto nos pré e pós-testes. MAR é o sujeito que apresentou maior dificuldade para generalizar pois, ainda na $13^{a}$ exclusão, não lia qualquer das palavras apresentadas. Os dados com a porcentagem de leitura correta nas etapas de exclusão dos sujeitos do G1 não estão apresentados tendo em vista que, para todos os sujeitos, o valores percentuais de leitura correta situam-se praticamente entre 95 e $100 \%$, indicando, com isso, controle do procedimento sobre a aquisição de leitura.

$\mathrm{Na}$ Figura 3 encontram-se as porcentagens de leitura correta nas fases de equivalência, nos testes de retenção de leitura após o período de férias e nos Testes 1 e 2 . Dos três sujeitos, logo após o período de férias, EZE é o que apresenta maior porcentagem (96\% de leitura das palavras-treino, vindo a seguir o sujeito MAR (83\%) e, por último, o sujeito RAF (58 \%), o mesmo ocorrendo em relação às palavras de generalização $(100,60$ e $0 \%$ respectivamente para EZE, MAR e RAF). Em relação à porcentagem de leitura das palavras-treino do Teste 1, o percentual de leitura correta é semelhante para todos os sujeitos (100\%), o mesmo não ocorrendo com o percentual de leitura das palavras de generalização, que é maior para os sujeitos EZE (81\%) e RAF $(75 \%)$ e menor para o sujeito MAR (50 \%). Por sua vez, o percentual de leitura correta das palavras-treino no Teste 2 é $100 \%$ para todos os sujeitos; em relação às palavras de generalização, há uma pequena diferença nos percentuais obtidos por EZE (100\%) e os sujeitos RAF e MAR (com $97 \%$ para ambos). Nos Testes de Equivalência, as porcentagens não se diferem entre os três sujeitos, com 100 $\%$ de leitura correta. 


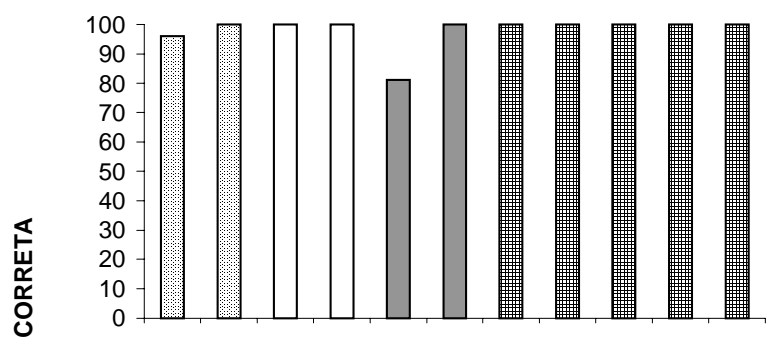

EZE

RAF
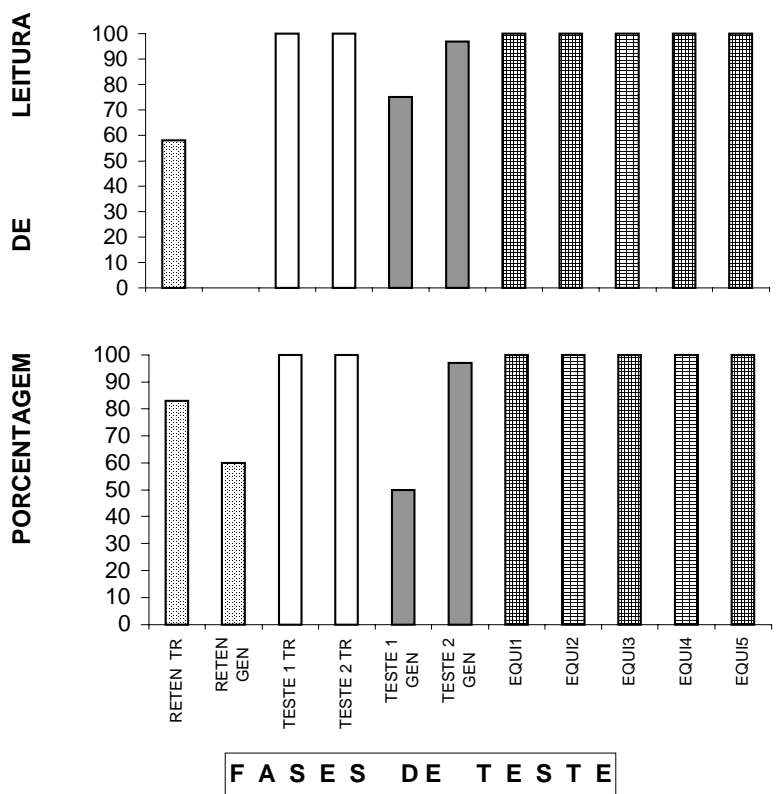

MAR

Figura 3. Porcentagem de leitura correta nas fases de teste (RETEN TR: retenção [após o período de férias] das palavras-treino; RETEN GEN: retenção das palavras de generalização; TESTE 1 e 2 [TR e GEN]: testes realizados durante o procedimento; EQUI [1, 2, 3, 4 e 5]: testes realizados durante o procedimento). 
200 J.G. Medeiros e S.A. Teixeira

Tabela 1. Resultados brutos obtidos pelos sujeitos dos Grupos 1 e 2 nas aplicações do teste de QI a que foram submetidos.

\begin{tabular}{|c|c|c|c|c|c|}
\hline \multirow{4}{*}{\begin{tabular}{|c|c}
\multicolumn{1}{c}{$\mathbf{G 1}$} \\
QI VERBAL \\
QI EXEC
\end{tabular}} & \multicolumn{2}{|c|}{ EZE } & \multicolumn{2}{|c|}{ RAF } & MAR \\
\hline & ANTES & DEPOIS & ANTES & DEPOIS & ANTES DEPOIS \\
\hline & 74 & 86 & 76 & 74 & 86 \\
\hline & 47 & 61 & 61 & 69 & 80 \\
\hline & & & & & CLO \\
\hline & ANTES & DEPOIS & ANTES & DEPOIS & ANTES DEPOIS \\
\hline QI VERBA & 90 & 95 & 97 & 101 & 85 \\
\hline QI EXEC & 89 & 78 & 93 & 94 & 80 \\
\hline
\end{tabular}

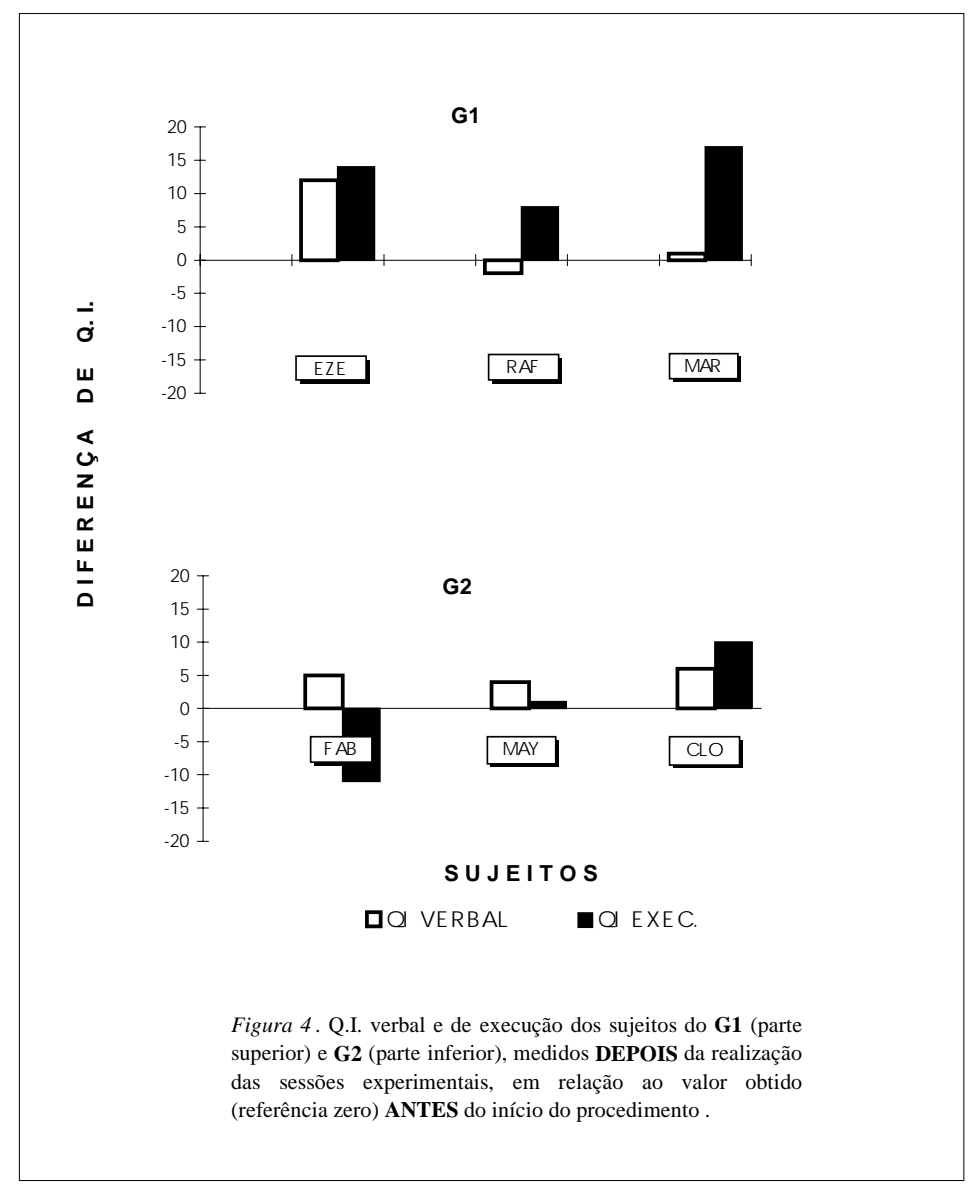


Na Tabela 1 encontram-se os resultados obtidos no teste de QI e na Figura 4 encontra-se a diferença de QI obtida entre a primeira e segunda aplicação para os sujeitos do G1 e G2. No G1 (parte superior da Figura), o QI de EZE alterou-se para mais, tanto no nível verbal como no de execução, com 12 e 14 pontos em relação ao valor obtido na primeira aplicação (valor de referência - aqui convencionado como 0 para efeito de visualização). O sujeito RAF, por sua vez, apresentou alteração não consistente no Q.I, com diminuição (-2 pontos) no verbal e aumento (+8 pontos) no de execução. O QI de MAR alterou-se para mais em execução (+18 pontos) em relação ao valor de referência; em verbal, o aumento é da ordem de 2 pontos.

No G2 (parte inferior da Figura), o QI verbal de FAB aumentou 5 pontos e o de execução diminuiu 10 pontos; o QI do sujeito MAY aumentou, tanto no verbal quanto no de execução (4 e 1 pontos respectivamente). O do sujeito CLO apresenta-se com alteração positiva nas duas modalidades do QI, com aumento de 6 pontos em verbal e 10 pontos em execução.

Na parte superior da Figura 5, são apresentados os percentuais de leitura correta das palavras de generalização dos sujeitos do G1 no Teste de Retenção e nos Testes 1 e 2 e, na parte inferior da Figura, os QIs verbal e de execução correspondentes. Todos os sujeitos apresentaram leitura generalizada, ao nível de $100 \%$ de acertos, no último teste (Teste 2). Pode-se ainda verificar que, entre os três sujeitos, é EZE quem apresenta melhor desempenho nos testes de QI, com aumento tanto no QI verbal (12 pontos) quanto no QI de execução (14 pontos); o segundo melhor desempenho pertence ao sujeito MAR que apresenta pequeno aumento (1 ponto) no QI verbal e o maior aumento (17 pontos), entre os três sujeitos, no QI de execução e, por último, o sujeito RAF que apresenta aumento de 8 pontos no QI de execução, contudo seu QI verbal sofre uma diminuição de 2 pontos.

A Figura 6 apresenta os resultados do IAR, obtidos antes do início do estudo e os resultados obtidos após o seu término, tanto para o G1 (à esquerda da Figura) quanto para o G2 (à direita da Figura). Houve alteração positiva (histogramas cinzas) no desempenho de todos os sujeitos do G1 (MAR: itens 1, 2, 8, 11, 12 e 13; RAF: itens 2, 

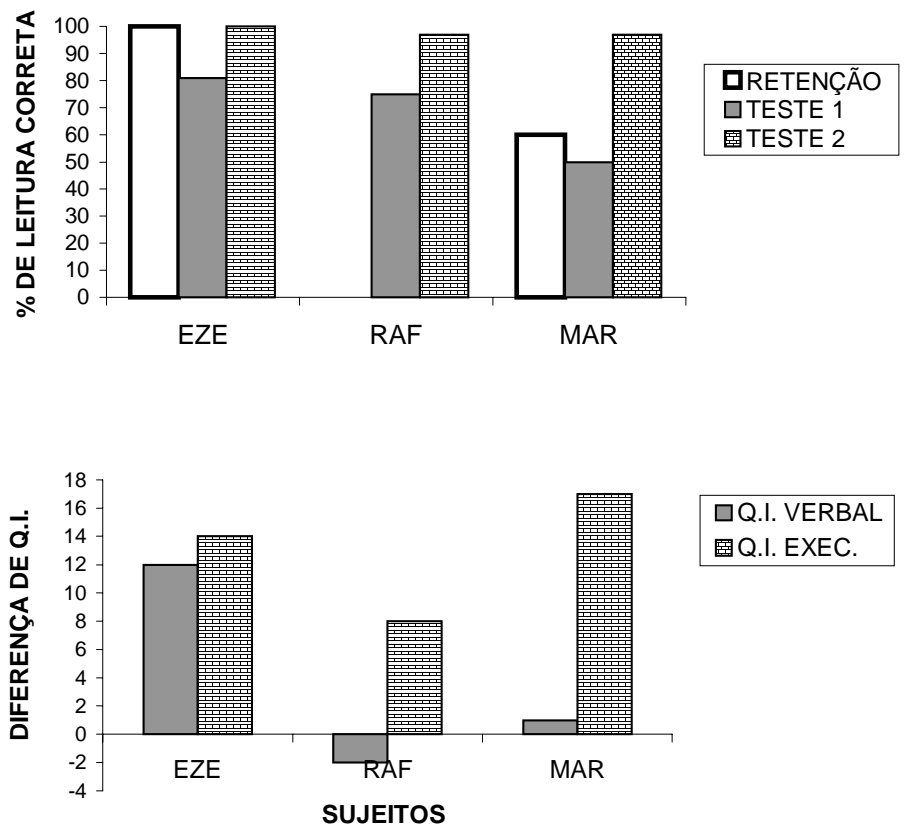

Figura 5. Porcentagem de leitura correta (parte superior) das palavras de generalização nos testes 1,2 e de retenção dos sujeitos do Grupo 1. Na parte inferior da Figura encontram-se os valores numéricos da diferença de QI entre a 1a. e 2a. aplicação dos mesmos sujeitos.

3, 5, 7, 10, 12 e 13; EZE: itens 1, 2, 6, 9, 10, 12 e 13). Ocorreu também alteração positiva (histogramas cinzas) no desempenho dos sujeitos do G2 (FAB: ítens 1, 2, 11, 12 e 13; MAY: 6e 12; CLO: 3, 9, 10,11,12 e 13) porém em proporção menor: em 20 itens para os sujeitos do G1 e em 13 itens para os sujeitos do G2.

A Tabela 2 apresenta os itens do IAR, com os dados agrupados e organizados em três categorias: itens com 100\% de acertos, itens abaixo de $100 \%$ de acertos e itens não alterados Pode ser verificado que a diferença percentual dos itens com $100 \%$ de acertos entre a primeira e segunda aplicação, no G2, é da ordem de 15,4e, no G1, a diferença é da 
ordem de 25,6. Se comparar-se os valores percentuais dos itens com aumento, verifica-se que, no G1, a diferença é também maior $(51,3)$ para este do que para o G2 $(33,4)$. Em relação aos itens não alterados, a porcentagem é maior $(53,8)$ para o G2 do que para o G1 $(38,5)$. Em relação aos ítens com diminuição não há, praticamente, diferença entre os grupos.
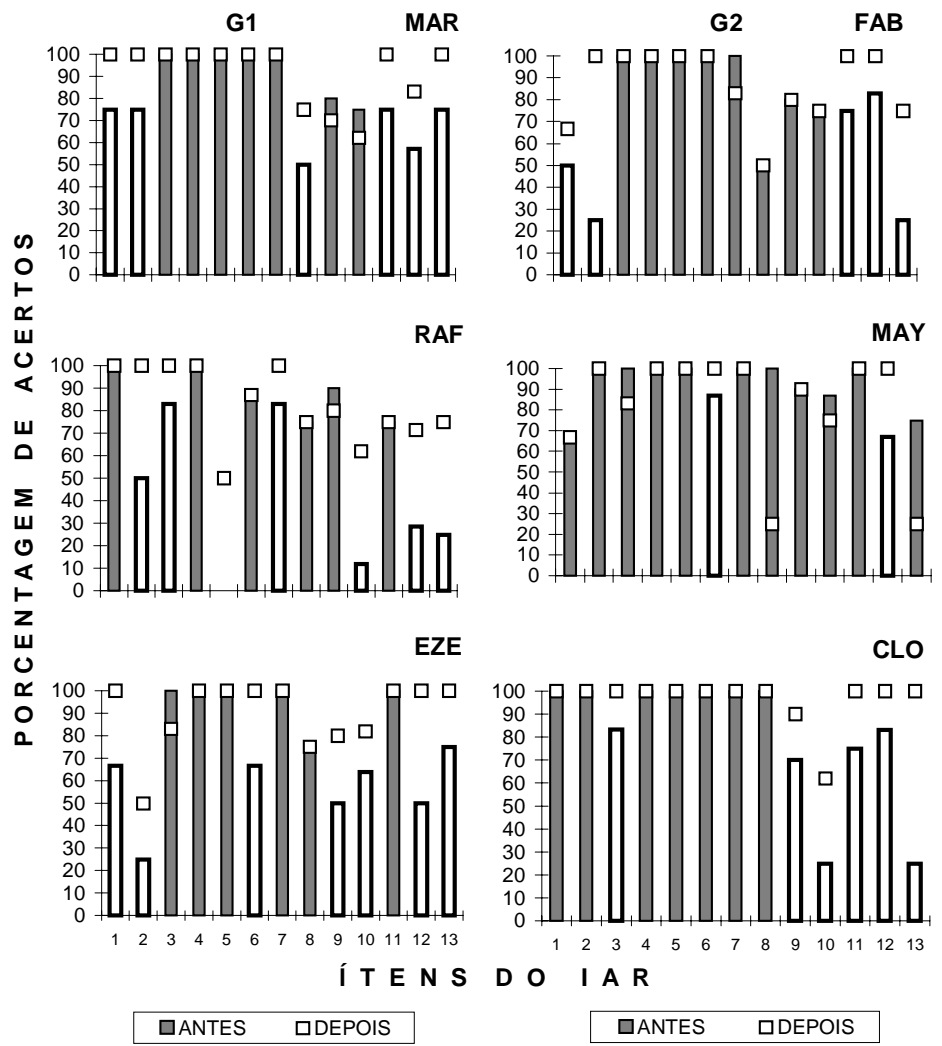

Figura 6. Porcentagem de acertos dos sujeitos do $\boldsymbol{G} \boldsymbol{1}$ e $\boldsymbol{G} \mathbf{2}$, nos ítens de 1 a 13 que compõem o IAR, antes do início do estudo e após o seu término. Os ítens nos quais a porcentagem aumentou estão em destaque (histogramas brancos com bordas largas). $\mathbf{1}=$ Esquema corporal; $\mathbf{2}=$ Lateralidade; $\mathbf{3}=$ Posição; $\mathbf{4}=$ Direção; $\mathbf{5}=$ Espaço; $\mathbf{6}=$ Tamanho; $\mathbf{7}$ Quantidade; 8= Forma; 9= Discriminação visual; 10= Discriminação auditiva; 11= Verbalização de palavras; 12= Análise-síntese; 13= Coordenação-motora . 
204 J.G. Medeiros e S.A. Teixeira

Tabela 2. Diferença em porcentagem dos itens com $100 \%$ de acertos, dos itens abaixo de $100 \%$ de acertos, dos itens com aumento de acertos, dos itens não alterados e dos itens com diminuição de acertos entre os resultados obtidos ANTES do início do trabalho e DEPOIS de seu término.

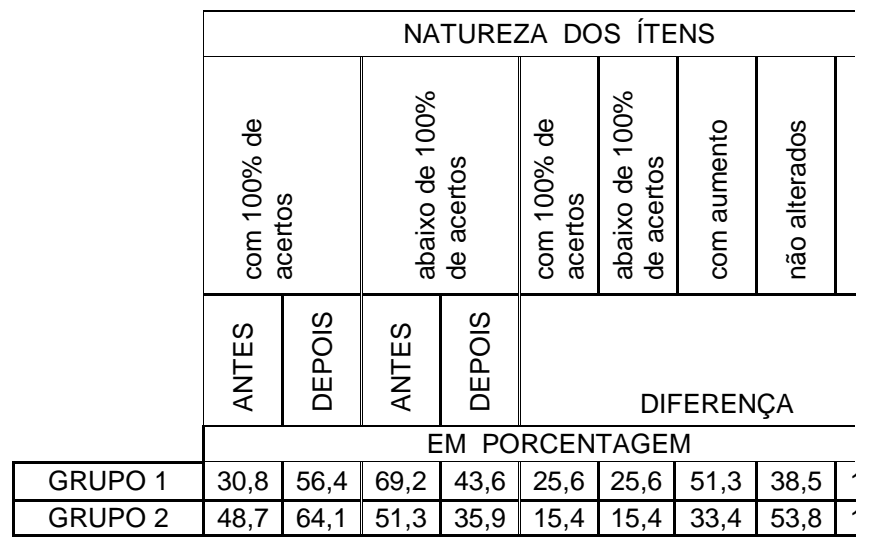

Tabela 3. Média dos ganhos dos G1 e G2 resultante da diferença entre os resultados obtidos na primeira e segunda aplicação do IAR e a respectiva significância de cada um dos ítens.

\begin{tabular}{|c|c|c|c|}
\hline ITEM & $\begin{array}{c}\text { GANHOS } \\
\text { DO G1 }\end{array}$ & $\begin{array}{c}\text { GANHOS } \\
\text { DO G2 }\end{array}$ & SIGNIFICÂNCIA \\
\hline 1. Esquema corporal & 19,4 & 05,6 & 0,293 \\
\hline 2. Lateralidade & 33,3 & 25,0 & 0,768 \\
\hline 3. Posição & 11,3 & 11,3 & 0.981 \\
\hline 4. Direção & 00,0 & 00,0 & - \\
\hline 5. Espaço & 16,7 & 00,0 & 0,374 \\
\hline 6. Tamanho & 11,1 & 05,7 & 0,685 \\
\hline 7. Quantidade & 05,7 & 05,7 & 1,00 \\
\hline 8. Forma & 08,3 & 25,0 & 0,561 \\
\hline 9. Discriminação visual & 16,7 & 06,7 & 0,349 \\
\hline 10.Discriminação auditiva & 27,7 & 16,3 & 0,511 \\
\hline 11.Verbalização de palavras & 08,3 & 16,7 & 0,519 \\
\hline 12.Análise-síntese & 28,6 & 22,3 & 0,535 \\
\hline 13.Coordenação-motora & 25,0 & 58,3 & 0,116 \\
\hline TOTAL & 16,3 & 15,3 & 0,814 \\
\hline
\end{tabular}


Se se comparar a média dos ganhos obtidos em cada um dos itens, não se verifica diferença entre eles. A Tabela 3 apresenta a média resultante da diferença entre os resultados obtidos na primeira e segunda aplicação e os índices de significância de cada um dos 13 itens que compõem o IAR. Como pode ser verificado não há diferença significativa ao nível de 0,05 em nenhum dos itens.

\section{Discussão}

Procurou-se verificar que alterações ocorreriam no quociente de inteligência (QI) das crianças do G1, após as mesmas terem sido submetidas a um procedimento de discriminação condicional. $\mathrm{O}$ instrumento utilizado para medir foi o teste de inteligência WISC ${ }^{3}$. Como descrito anteriormente, a alteração mais consistente ocorreu no QI de execução dos sujeitos do G1.

Quanto aos resultados da aplicação do WISC, no sub-grupo execução ${ }^{4}$, em relação aos sujeitos do G2, o QI de FAB sofreu variação negativa de 10 pontos, ou seja, tornou-se menos hábil nas provas testadas. O de MAY praticamente não apresenta alteração. CLO, que deixou de freqüentar a escola aproximadamente três meses antes da segunda aplicação do IAR e WISC ${ }^{5}$, é, entre os três, o que apresenta melhor desempenho no IAR, com aumento em seis ítens (ver Figura 6) e o único que apresenta variação positiva do QI; diversas são as variáveis que podem ter interferido no aumento de seu Q.I, entre elas o fato de ter se ausentado da escola, indicando que a instituição escolar está impedindo mais do que favorecendo o desempenho escolar; semelhante afirmativa apoia-se no fato de que o QI de execução de uma das duas crianças que continuou freqüentando as aulas não se alterou (MAY) e, para a outra, ocorreu diminuição (FAB). Resta ainda perguntar se a aplicação dos testes na residência do sujeito não teria favorecido o desempenho.

Os sujeitos do G1, por sua vez, com um QI de execução alterado, cujo aumento situa-se entre 8 e 18 pontos, demonstraram maior habilidade nas respostas ao teste, tanto em relação a si mesmos (primeira e segunda aplicação) como em relação aos sujeitos do G2. O QI verbal de RAF e MAR praticamente não apresenta alteração. Já o sujeito 
EZE aumentou consideravelmente seu QI verbal (14 pontos). As provas que fazem parte do subgrupo verbal ${ }^{6}$ e das quais não possuímos indicativos que possibilitem relacionar o efeito do procedimento ao aumento do QI dos sujeitos são: informação, compreensão (que testa a habilidade geral para avaliar experiências passadas), aritmética, semelhança e números (que testa habilidades para memorizar dígitos mecanicamente etc.). $\mathrm{O}$ treino em discriminações condicionais não visou diretamente o desenvolvimento destas habilidades, porém, é possível ter havido algum nível de generalização em relação a elas.

O mesmo não acontece em relação ao QI de execução, pois há indicativos da existência de relações entre o aumento de QI deste subgrupo com os resultados decorrentes do procedimento de discriminação condicional. Os sujeitos que participaram deste procedimento apresentaram, no Teste 2, $100 \%$ de leitura correta das palavrastreino e das palavras de generalização. No caso do IAR, a diferença entre os resultados da primeira e segunda aplicação dos sujeitos do G2 é menor que a diferença entre as aplicações a que foram submetidos o sujeitos do G1, ou seja, o desempenho dos sujeitos do G1 no IAR foi superior ao desempenho dos sujeitos do G2; esta diferença pode ser devida ao procedimento de ensino de relações discriminativas a que foram submetidos, resguardada a possibilidade desta diferença não existir se os percentuais das categorias de análise (itens com $100 \%$ de acertos, itens abaixo de $100 \%$ de acertos e itens não alterados) dos dois grupos fossem aproximadamente semelhantes.

Os resultados sugerem que a ocorrência de generalização combinada de leitura, composição e montagem de anagramas, está associada a um aumento no QI de execução, medido pelo WISC. Esse resultado está condizente com aqueles obtidos no estudo realizado por de Rose et al. (1993) no qual os três sujeitos do grupo experimental que apresentaram generalização de leitura e escrita também apresentaram aumento no QI.

A avaliação psicológica através de testes supõe que a relação entre inteligência e aprendizagem é de natureza unidirecional, ou seja, da inteligência para a aprendizagem. Esta relação linear tradicional está sendo superada pela "influência da aprendizagem na inteligência" (Almeida, 1992). 
A concepção do significado de inteligência está impregnada de acentuado relativismo cultural; o conceito de inteligência, segundo Marques (1987), está equacionado com necessidades e aspirações culturais e sociais que se relacionam a valores e finalidades que são históricas e socialmente produzidas.

Os resultados do presente estudo assemelham-se, em parte, aos resultados obtidos por de Rose et al. (1993); para todos os sujeitos do G1 houve aumento de QI, subseqüente à ocorrência de generalização, muito embora este aumento tenha sido sistematicamente no QI de execução. Ao contrário, os sujeitos do G2 não apresentaram variação positiva no QI, com exceção de um sujeito deste grupo que apresentou alteração positiva, mas que, havia se ausentado da Escola nos três últimos meses antes do reteste. Fica então a pergunta: será que o ensino, principalmente aquele que não leva em consideração o capital cultural das crianças, não estaria prejudicando o seu desenvolvimento?

Algumas variáveis não foram controladas como, por exemplo, informações mais detalhadas dos sujeitos que pertenciam a cada um dos grupos e a ausência de observação do que ocorria em sala de aula, tanto do comportamento dos sujeitos do G2, quanto dos sujeitos do G1. De fato, a ausência de conhecimento mais detalhado a respeito dos sujeitos que compuseram os grupos constitui-se num problema quando procura-se compará-los. Na Tabela 1 e Figura 6, pode-se verificar que, na aplicação prévia dos testes (QI e IAR), os resultados que serviram como Linha de Base são diferentes: o desempenho dos sujeitos do G2 foi superior ao desempenho dos sujeitos do G1 em ambos os instrumentos de medida. Ainda, assim, no reteste, pode-se verificar que o aumento do QI de execução dos sujeitos do G1 foi sistemático, ou seja, aumentou para os três sujeitos, enquanto que o mesmo não ocorreu com os sujeitos do G2, onde para um sujeito (FAB) há diminuição e, para outro (MAY), o aumento é de apenas um ponto; a exceção foi o terceiro sujeito (CLO) que, semelhantemente aos sujeitos do G1, teve o QI aumentado entre uma aplicação e outra. Como foi dito anteriormente, este sujeito ausentou-se da Escola por um período de três meses antes do reteste. Isto pode, evidentemente, levantar a questão de que a Escola precisa intervir de maneira diferen- 
ciada em relação ao desempenho de crianças com histórias de fracasso escolar e o procedimento realizado pode ser considerado um exemplo desta intervenção. Poderia até se perguntar se a Escola não estaria impedindo mais do que favorecendo o desenvolvimento dessas crianças. A elevada evasão deste tipo de população não estaria "falando" a favor desta hipótese?

Uma outra questão a ser discutida refere-se à indicação, realizada pela professora, dos participantes deste trabalho. Feita a indicação, os sujeitos foram submetidos à aplicação dos testes ${ }^{7}$. Os que apresentaram desempenho inferior fizeram parte do G1 e os que apresentaram desempenho superior fizeram parte do G2. Procedeu-se, desta maneira, em decorrência da característica deste trabalho, isto é, uma pesquisa realizada num contexto de aplicação. Interessava-nos, prioritariamente, estender os benefícios do procedimento de equivalência de estímulos a crianças com dificuldades de aprendizagem. Assim, como visto nas Tabelas 1 e 2, tanto o QI verbal/execução quanto os resultados do IAR do sujeitos do G2 são, no pré-teste, superiores aos obtidos pelos sujeitos do G1.

Essa ausência de homogeneização dos resultados da Linha de Base dificultou a comparação entre os grupos. Ainda assim, é possível mostrar que o QI de execução (re-teste) dos sujeitos do G1 é mais elevado que o QI dos sujeitos do G2. Semelhante diferença pode ser devida aos efeitos do procedimento de discriminação condicional que possibilita o estabelecimento de relações entre classes de estímulos diferentes. Assim, o desempenho em alguns itens do IAR, como em Discriminação Visual e em Discriminação Auditiva pode ter sido facilitado pelo treino das relações entre classes de estímulos auditivos e impressos e o desempenho em Coordenação Motora pode ter sido facilitado pelo treino da atividade de montagem das palavras. A alteração no desempenho dos sujeitos do G2, principalmente no IAR, pode ter sido devida aos efeitos das contingências de ensino em sala de aula.

Estudos com amostras maiores e linhas de base comportamentais mais semelhantes e sensíveis, como uma linha de base múltipla, entre os sujeitos que comporão os grupos, poderão mostrar se, de fato, os 
testes utilizados são sensíveis aos efeitos do procedimento de ensino de relações condicionais. A diferença não significativa nos itens do IAR (Tabela 3 ) entre os grupos pode ser devida, entre outros fatores, ao número reduzido (três) de sujeitos nos grupos e ao fato do desempenho no teste de Q.I do sujeitos do G2 ter sido superior ao desempenho dos sujeitos do G1 na primeira aplicação do teste. Convém lembrar que a professora da classe da qual essas crianças faziam parte indicou para participar do estudo aquelas que apresentavam maiores dificuldades nas atividades de leitura e escrita e, também, nos prérequisitos exigidos para a realização destas duas atividades.

\section{Agradecimentos}

Os autores agradecem o apoio financeiro concedido a Sonia Aparecida Teixeira através de bolsa de iniciação científica pelo Programa PIBIC UFSC/CNPq. Trabalho realizado com apoio do $\mathrm{CNPq}$ através de recursos provenientes de bolsa de produtividade em pesquisa (Processo 524166/96-0 NV).

\section{Referências}

Almeida, L. S. (1988). O impacto das experiências educativas na diferenciação cognitiva dos alunos: análise dos resultados em provas de raciocínio. Revista Portuguesa de Psicologia, 24, 131-157.

Almeida, L. S. (1992). Inteligência e aprendizagem: dos seus relacionamentos à sua promoção. Psicologia: Teoria e Pesquisa, 8 (3), 277- 292.

Anastasi , A. (1983). Evolving trait concepts. American Psychologist, 38, 175-184.

Bijou, S. W. (1976). Child development: the basic stage of early childhood. Englewood Clifts: Prentice Hall.

Carraher, T. N., Carraher, D. W. e Schliemann, A. D. (1987). A inteligência da criança brasileira: as controvérsias em pauta. Psicologia, Ciência e Profissão, 7 (1), 20.

Chiarottino, Z. R. (1972). Piaget: modelo e estrutura. Rio de Janeiro: José Olympio.

Chiarottino, Z. R., Carraher, D. W., \& Shchliemann, A. D. (1987). A inteligência da criança brasileira. Psicologia, Ciência e Profissão, 7 (1), 21-24.

de Rose, J.C. (1988). Equivalência de estímulos: problemas atuais de pesquisa. Workshop: Avanços recentes em análise experimental do comporta- 
mento: novos problemas e novas soluções. In Sociedade de Psicologia de Ribeirão Preto (Org.), Anais da 18 ${ }^{a}$. Reunião Anual de Psicologia (pp.1932). Ribeirão Preto: SPRP.

de Rose, J. C. C., Souza, D. G. de, Hanna, E. S., Fonseca, M. L., Santos, L. G. dos, Guimarães, L. B., Balduino, L. H., Souza, J. A. N., \& Melchiori, L. E. (1993). Aprendizagem de leitura aumenta o quociente intelectual de criança com desempenho acadêmico insuficiente. In Sociedade Brasileira de Psicologia (Org.), Comunicações Científicas em Psicologia (p. 303). Ribeirão Preto: SBP.

de Rose, J. C. C., Souza, D. G., Rossito, A. L., \& de Rose, T. M. S. (1989). Equivalência de estímulos e generalização na aquisição da leitura após história de fracasso escolar. Psicologia, Teoria e Pesquisa, 5, 325-346.

de Rose, J. C. (1993). Classes de estímulos: implicações para uma análise comportamental da cognição. Psicologia, Teoria e Pesquisa, 9 (2), 283-303.

Hanna, E. S., Souza, D. G., de Rose, J. C., Santos, L. G., Fonseca, M. L., Horowitz, D. B., Carvalho, G. P., Sallorenzo, L. H., Balduíno, L. H., \& Veiga, H. (1993). Treino de cópia com resposta construída e o desempenho em ditado II : efeitos dependentes do nível de generalização na linha de base de leitura. In Sociedade Brasileira de Psicologia (Org.), Resumos da Reunião Anual de Psicologia (p.305). Ribeirão Preto: SBP.

Leite, S. A. S. (1984). Alfabetização: uma proposta para a escola pública. Cadernos de Pesquisa, 52, 25-32.

Mackay, H., \& Sidman, M. (1984). Teaching new behavior via equivalence relations. In P. H. Brooks, R. Sperber e C. McCauley (Orgs.). Learning and cognition in the mentally retarded (pp. 493-513). Hillsdale: Erlbaum.

Mackay, H. A. (1985). Stimulus equivalence in rudimentary reading and spelling. Analysis and Intervention in Developmental Disabilities, 5, 373 387.

McDonagh, E., McIlvane, W. J., \& Stoddard, L. T. (1984). Teaching coin equivalences via matching to sample. Applied Research in Mental Retardation, 5, 177-197.

Marques, J. C. (1987). O significado da inteligência: dimensões cognitivas, sócio-políticas e existenciais. Psicologia: Reflexão e Crítica, 2, (1/2).

Medeiros, J. G., Konescki, G. E., \& Souza, A. P. (1993). Alternativa de alfabetização para crianças com dificuldades de aprendizagem em leitura e escrita. In Departamento de Apoio à Pesquisa (Org.), Anais do III Seminário Catarinense de Iniciação Científica (p. 50). Florianópolis: DAP.

Medeiros, J. G., Monteiro, G., \& Silva, K. Z. (1997). Aquisição de leitura e escrita por um sujeito adulto. Temas em Psicologia, 1, 65-78.

Medeiros, J. G., Antonakopoulu, A., Amorim, K., \& Righetto, A. C. (1997). O uso da discriminação condicional no ensino da leitura e escrita. Temas em Psicologia, 1, 23-32. 
Medeiros, J. G. (1997). Relato de uma experiência de ensinar: construindo a relação entre teoria e prática. Temas em Psicologia, 1, 7-22.

Neto, R. B. (1994). QI mede comportamento inteligente. Folha de São Paulo, São Paulo, 30 out. Caderno Mais, p. 4.

Ribes, E. (1981). Reflexiones sobre el concepto de inteligencia y su desarrollo. Simpósio Interamericano sobre el Desarrollo de la Inteligencia (CINTERPLAN). Ciudad Guyana, Venezuela.

Schoenfeld, W. N. (1974). Notes on a bit of psychological nonsense: race differences in intelligence. Psychological Record, 24, 17-32

Sidman, M., \& Tailby, W. (1982). Conditional discrimination vs. matching to sample: an expansion of the testing paradigm. Journal of the Experimental Analysis of Behavior, 37, 5-22.

Singh, N. N., \& Singh, J. (1986). Reading acquisition and remediation in the mentally retarded. In N. R. Ellis e N. W. Bray (Orgs.), International review of research in mental retardation (vol. 14, pp. 165-199). New York: Academic Press.

Stromer, R. (1991). Equivalência de estímulos: implicações para o ensino. In W. Ishaq (Org.). Human behavior in today's world (pp.109-122). New York: Praeger.

Stromer, R., \& Mackay, A. H. (1992). Delayed constructed-response identify matching improves the spelling performances of students with mental retardation. Journal of Behavioral Education, 2, 139-158 .

Wechsler , D. (1949). Escala de inteligência para crianças. Rio de Janeiro: CEPA. 
por sua vez, são: (a) uso de um outro teste no estudo de Medeiros, além do WISC, para medir pré-requisitos para a alfabetização, denominado IAR; (b) no estudo de Medeiros, os sujeitos do Grupo 2 (G2) foram apenas submetidos aos testes (WISC e IAR), contudo no estudo de de Rose, os sujeitos do Grupo Controle foram submetidos a uma versão modificada do Programa, que envolveu atividades de cópia das palavras com letras isoladas e foram também submetidos a avaliações periódicas de leitura e escrita.

2 Evitou-se denominar os grupos de Experimental e Controle por quatro razões: (1) esta denominação é mais apropriadamente empregada em delineamentos inter-grupos; (2) os sujeitos foram alocados nos grupos em condições de desempenho diferenciadas (os de Q.I mais baixo fizeram parte do G1 e os de Q.I. mais alto fizeram parte do G2); (3) a análise dos dados baseou-se tanto em comparações intra-sujeitos (sujeitos como seu próprio controle), quanto em comparações inter-sujeitos (comparações entre grupos) e (4) empregou-se mais a análise descritiva do que a análise estatística.

3 O percentual considerado normal, ou seja, o Q.I médio esperado, oscila no intervalo de 95 a 105.

4 As provas deste subgrupo são constituídas por: completar figuras (agilidade e memória visual/discriminação de detalhes/atenção concentrada/habilidade de reconhecer formas); arranjo de figuras 
(planejar ação através da organização visual e captação de sequiência das figuras com sentido/compreensão de situações práticas da vida diária); cubos (habilidade na organização e coordenação viso-manual/capacidade para analisar e sintetizar/capacidade para executar tarefas); armar objetos (percepção imediata do todo/habilidade na antecipação e organização viso-motora; síntese de formas concretas); código ou labirinto (velocidade na aprendizagem/ reprodução escrita de símbolos/capacidade de harmonia entre a organização visual e ação motora; planejamento e seguimento de modelo visual/velocidade e precisão).

5 A bolsista teve de aplicar os testes finais na residência do sujeito.

${ }^{6}$ As provas deste subgrupo são constituídas por: informação (informação e eficiência da memória); compreensão (conhecimento prático e julgamento moral); aritmética (raciocínio aritmético e concentração); semelhanças (capacidade de pensamento lógico e abstrato); vocabulário (conhecimento de palavras por experiência e educação).

7 A composição dos grupos ocorreu com base nos resultados do teste de QI.

José Gonçalves Medeiros, doutor em Psicologia ExperimenSobre os autores tal pela Universidade de São Paulo, é professor do Departamento 
214 J.G. Medeiros e S.A. Teixeira

de Psicologia da Universidade Federal de Santa Catarina. Endereço para correspondência: Campus Universitário UFSC, Caixa Postal 5060, Bairro da Trindade, 88040-970, Florianóplois, SC. Fones: $(0 * * 48)$ 331-9984 e $(0 * * 48)$ 972-4042. Email:medeiros@mbox1.ufsc.br.

Sonia Aparecida Teixeira é bolsista de Iniciação Científica do Programa PIBIC/CNPq. 